\title{
Affordable Biocidal Ultraviolet Cured Cuprous Oxide Filled Vat Photopolymerization Resin Nanocomposites with Enhanced Mechanical Properties
}

\author{
Markos Petousis ${ }^{1} * \mathbb{D}$, Nectarios Vidakis ${ }^{1}$, Emmanuel Velidakis ${ }^{1}$, John D. Kechagias ${ }^{2} \mathbb{D}$, Constantine N. David ${ }^{3}$, \\ Stefanos Papadakis ${ }^{4}$ and Nikolaos Mountakis ${ }^{1}$ \\ 1 Mechanical Engineering Department, Hellenic Mediterranean University, Estavromenos, \\ 71410 Heraklion, Greece; vidakis@hmu.gr (N.V.); m.velidakis@hmu.gr (E.V.); mh90@edu.hmu.gr (N.M.) \\ 2 General Department, University of Thessaly, 41500 Larissa, Greece; jkechag@uth.gr \\ 3 Manufacturing Technology \& Production Systems Laboratory, School of Engineering, \\ International Hellenic University, Serres Campus, 62124 Serres, Greece; david@ihu.gr \\ 4 Biology Department, University of Crete, Voutes University Campus, P.O. Box 2208, 70013 Heraklion, Greece; \\ stefpap@biology.uoc.gr \\ * Correspondence: markospetousis@hmu.gr; Tel.: +30-2810-37-9227
}

\section{check for}

updates

Citation: Petousis, M.; Vidakis, N.; Velidakis, E.; Kechagias, J.D.; David, C.N.; Papadakis, S.; Mountakis, N. Affordable Biocidal Ultraviolet Cured Cuprous Oxide Filled Vat Photopolymerization Resin Nanocomposites with Enhanced Mechanical Properties. Biomimetics 2022, 7, 12. https://doi.org/ 10.3390/biomimetics7010012 Academic Editor: Stanislav N. Gorb Received: 20 December 2021 Accepted: 7 January 2022 Published: 10 January 2022 Publisher's Note: MDPI stays neutral with regard to jurisdictional claims in published maps and institutional affiliations.

Copyright: (C) 2022 by the authors. Licensee MDPI, Basel, Switzerland. This article is an open access article distributed under the terms and conditions of the Creative Commons Attribution (CC BY) license (https:// creativecommons.org/licenses/by/ $4.0 /)$.

\begin{abstract}
In this study, Cuprous Oxide $\left(\mathrm{Cu}_{2} \mathrm{O}\right)$, known for its mechanism against bacteria, was used as filler to induce biocidal properties on a common commercial resin stereolithography (SLA) 3D printing resin. The aim was to develop nanocomposites suitable for the SLA process with a low-cost process that mimic host defense peptides (HDPs). Such materials have a huge economic and societal influence on the global technological war on illness and exploiting 3D printing characteristics is an additional asset for these materials. Their mechanical performance was also investigated with tensile, flexural, Charpy's impact, and Vickers microhardness tests. Morphological analysis was performed through scanning electron microscopy (SEM), atomic force microscopy (AFM), and energydispersive X-ray spectroscopy (EDS) analysis, while the thermal behavior was studied through Thermogravimetric Analysis (TGA). The antibacterial activity of the fabricated nanocomposites was investigated using a screening agar well diffusion method, for a gram-negative and a gram-positive bacterium. Three-dimensional printed nanocomposites exhibited antibacterial performance in all loadings studied, while their mechanical enhancement was approximately $20 \%$ even at low filler loadings, revealing a multi-functional performance and a potential of Cuprous Oxide implementation in SLA resin matrices for engineering and medical applications.
\end{abstract}

Keywords: stereolithography (SLA); 3D printing; antibacterial; additive manufacturing (AM); Cuprous Oxide; resin; mechanical; nanocomposites

\section{Introduction}

The discovery of the antibiotic penicillin in 1928 significantly transformed medicine, while the prolonged use of antibiotics ever since has necessitated the development of other treatments, with antibiotic-resistant bacteria affecting at least 2 million people each year, according to the Centers for Disease Control and Prevention (CDC) [1]. Microbial contamination of air, water, and soil by various microorganisms causes issues in living situations, as well as in public health and industry. As a result, antibiotic resistance genes have become more common in numerous bacterial species, including humans and animals [2]. The immunity system has mechanisms to inhibit or kill bacteria through the host defense peptide (HDP) and their physicochemical characteristics are imitated by synthetic (co)polymers [3], while metals, such as copper, silver, titanium, and zinc have characteristics that inhibit the growth of different bacteria, with their antibacterial efficacy verified in technologically appealing materials in fabrics, paints, and coatings that incorporate copper-based active 
granules or pigments [2]. Additionally, metal Nanoparticles (NPs) are the most promising in this field since they have exhibited significant antibacterial properties over the last few decades and have become more widely used in industry [4]. Different metallic and metal oxide nanoparticles (NPs) may have very promising and effective roles as antibacterial agents due to their enormous surface-to-volume ratio and crystalline shape, which elicit biological reactions that differ from those elicited by metals in their typical ionic form [5]. Still, the mechanisms underlying metallic nanostructures' biocidal action are not fully understood [5]. Physical contact between nanomaterials and bacteria, such as van der Waals interactions, electrostatic interactions, hydrophobic interactions, and receptor-ligand interactions, can result in membrane destruction, the inactivation of important cellular components, and bacteria death. Bacteria are classified into two groups based on the structure of their cell walls: gram-negative and gram-positive. Gram-negative bacteria have a thinner peptidoglycan layer than gram-positive bacteria because they have a unique outer membrane [6]. In this work, a gram-negative and a gram-positive bacterium were studied.

Over the last few decades, additive manufacturing (AM) has gained continuously increasing interest either at the academic or engineering level [7,8]. AM techniques are the most promising manufacturing methods for the industrial sectors in the future [9]. Applications have already been implemented in the automotive [10-12], electronics [13-16], packaging [17-20], medical, [21-24], and other economic sectors. Existing AM technologies have differences not only in their operating principles but also in the materials utilized in each method [25,26]. Apart from these differences, all AM techniques share the same layerby-layer manufacturing principle [27]. Commercially known AM technologies are fused filament fabrication (FFF), selective laser sintering (SLS), and stereolithography (SLA) [28]. FFF has been widely utilized even for home usage [27,29]. Consequently, sufficient research has been conducted on the materials of this AM technique, providing a continuously widening variety of composite materials with enhanced mechanical [30-34], thermal, [35-37], and other properties. In SLS, a laser beam melts the raw material, which is a powder form. The process has great ability to make end products for most industrial applications due to its build accuracy, high productivity for customized and complex-shaped things, and strong mechanical qualities [38]. For this reason, it has been used in several industrial and scientific fields, from prototypes to the fabrication of spare parts and small series in automotive and aerospace fields, to customized prostheses for biomedical applications [39]. SLA is an AM technique based on the photosensitivity of utilized materials [40], which are met in liquid form and are most known as ultraviolet (UV)-cured resins [41]. Liquid resins are poured in a transparent bottom tank, and a light source with a spot on the micro-scale is electronically driven to initiate the curing of the resin [42]. This process is repeated, and the final 3D printed part emerges on the build platform of the 3D printer. The light source type is the fundamental difference between SLA, digital light processing (DLP), and liquid crystal display (LCD) technologies [43]. The latter method has driven the price of UV resin 3D printers to low levels, consequently making them a competitor to the FFF process for everyday utilization [44].

Even enough studies have been conducted in the general field of resin composites [24,45], nanotechnology and especially the utilization of nanoparticles could provide a potential in photosensitive resin nanocomposites [46]. The SLA 3D printing technology usually produces parts with small layer heights. The most common layer height setup is 50 microns, and it is not prohibited to further lower the layer height to 25 microns or less [47]. Such small gaps between the build platform and the tank's bottom create difficulties in the 3D printing process, usually due to the high viscosity of the materials used and the "cups" effect $[47,48]$. Such problems have great potential to be resolved through the utilization of nanotechnology. Nanoscale size in combination with the high transferability of properties through fine particle dispersion in the matrix do not create big changes in the viscosity of the nanocomposite, and as a result, 3D printing does not require special procedures $[40,49]$. 
The recent Covid-19 pandemic situation has aroused the need for 3D printing utilization and its fully operational components [50]. Difficulties created in logistics and production rates were effortlessly resolved by enabling the 3D printing community worldwide [51,52]. Most known case studies involve the manufacturing of face shields and components of the respiratory valve machine [53-55]. Even though the main AM method utilized in these projects was FFF, SLA could provide optimized solidarity in parts and faster turnover times [56]. Medical applications require the utilization of materials with good mechanical performance and antibacterial properties [23,57], except for thermal stability. Materials with biomimetic characteristics have the potential to be used in a variety of applications and therapeutic delivery strategies to tackle antibiotic-resistant bacteria infection [1], while SLA already has sufficient implementation in the dental and wider medical sector; nevertheless, the properties of the materials used are not at the optimized level.

This work aimed to develop materials in a form suitable for SLA 3D printing, mimicking HDPs functionalities, to be suitable for use in corresponding engineering and medical applications. To achieve this, metals' biocidal properties were exploited. More specifically, a common SLA resin was utilized as a matrix material filled with Cuprous Oxide $\left(\mathrm{Cu}_{2} \mathrm{O}\right)$ at different loadings. Although Copper's mechanism of cell death is not yet fully known, Copper oxides $\left(\mathrm{CuO}\right.$ and $\left.\mathrm{Cu}_{2} \mathrm{O}\right)$ have a contact killing mechanism that causes significant damage to the cell membrane in bacteria [58]. Copper nanoparticles' antibacterial properties were attributed mostly to their ability to adhere to bacteria due to their opposite electrical charges, culminating in a reduction reaction at the bacterial cell wall [2]. The process for the preparation of the nanocomposites was implemented with common low-cost laboratory equipment. No similar research has been presented in the literature so far. $\mathrm{Cu}_{2} \mathrm{O}$ material antibacterial properties are thoroughly analyzed in literature [59], while the implementation of Cuprous Oxide nanoparticles in SLA resin matrices has not yet been studied, according to the authors' knowledge. The mechanical performance of the developed nanocomposites was also studied, and morphological and thermal analyses were performed to determine the effectiveness of the process. The antibacterial properties were analyzed using the screening method of agar well diffusion. The results showed that the implementation of nanoparticles in commercially utilized SLA resins has great potential, without the need for high-end technology equipment, since the nanocomposites developed exhibited antibacterial performance while having, at the same time, enhanced mechanical response.

\section{Materials and Methods}

\subsection{Materials}

For this study, a widely utilized commercially available resin was selected as the matrix material. Specifically, Formlabs Standard Clear V4 (Formlabs Ohio Inc., Millbury, OH, USA) was procured from a local supplier. Standard Clear V4 resin (SC), according to the manufacturer's safety data sheet, consists of $55-75 \%$ of urethane dimethacrylate, $15-25 \%$ methacrylate monomer(s), and less than $0.9 \%$ diphenyl (2,4,6-trimethybenzoyl) phosphine oxide. Such a composition of monomers enables the resin's photoreactive behavior for utilization in the stereolithography (SLA) AM technique. As a filler, an antibacterial reactor agent utilizing nanoparticles of Cuprous Oxide $\mathrm{I}\left(\mathrm{Cu}_{2} \mathrm{O}\right)$ was used. $\mathrm{Cu}_{2} \mathrm{O}$ nanopowder was procured from Nanografi (Nanografi Inc., Ankara, Turkey). It features an average particle size of $80 \mathrm{~nm}$. The nanopowder purity is $99.5 \%$, while the melting point of the material is $1.240^{\circ} \mathrm{C}$, according to the supplier's datasheet.

\subsection{Nanocomposites and Specimens Fabrication}

A high shear force mixer was utilized for the mixing procedure. SC resin was weighed and mixed with nanoparticles for filling ratios of $1.0 \mathrm{wt} . \%$ and $2.0 \mathrm{wt} . \%$ The mixing duration was $30 \mathrm{~min}$ to ensure the optimized dispersion of nanoparticles in the nanocomposites. Before the pure resin entered the 3D printer tank, a degasification procedure was conducted using a lab vacuum chamber at a room temperature of $21^{\circ} \mathrm{C}$. The $3 \mathrm{D}$ printer utilized for 
the SLA process was a Formlabs Form 2 (Formlabs Ohio Inc., Ohio, USA), equipped with a resin tank of Formlabs Tank LT. Form 2 was equipped with a laser light source with a wavelength of $450 \mathrm{~nm}$ and a laser spot of $150 \mu \mathrm{m}$. Slicing and gcode export were conducted using PreForm software version 3.16 (Formlabs Ohio Inc., Ohio, USA), and the layer height was fitted at 100 microns. All specimens were oriented with their largest surface on the build platform. After the 3D printing process, specimens were removed carefully from the build platform, and they were instantly emplaced in the Formlabs Form Wash machine. In this machine, they were washed in an isopropyl alcohol (IPA) solution of 90\% purity. The washing time was set according to the Formlabs specification at $10 \mathrm{~min}$. Afterward, the specimens were dried under room conditions $\left(22^{\circ} \mathrm{C}, 50 \% \mathrm{RH}\right)$. The final UV curing process was performed using a Formlabs Form Cure (Formlabs Ohio Inc., Ohio, USA) machine. Final curing was conducted for $30 \mathrm{~min}$ at $60{ }^{\circ} \mathrm{C}$. Figure 1 presents the fundamental 3D printing setting.

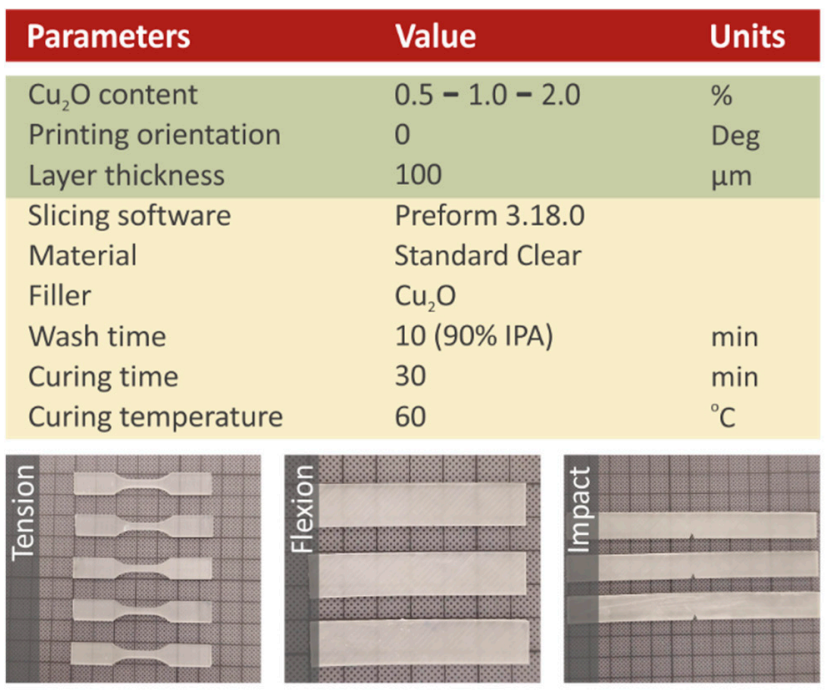

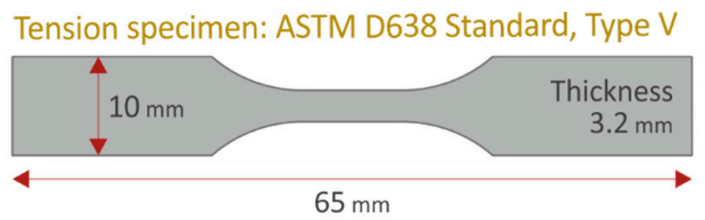

Flexion specimen: ASTM D790 Standard

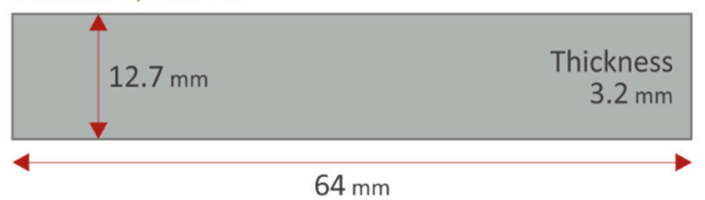

Charpy Notched specimen: ASTM D6110 Standard

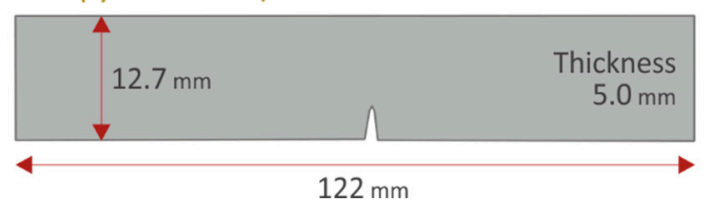

Figure 1. Fundamental SLA 3D printing settings, pictures, and sketches of the 3D printed specimens prepared in this work. Specimens were manufactured according to the corresponding American Society for Testing and Materials (ASTM) International Standard for each different type of test.

\subsection{Mechanical Performance Testing}

The mechanical properties were analyzed with tensile, flexural, impact, and Vickers microhardness testing. Tensile tests were conducted according to the ASTM D638-02a international standard on five (5) type $\mathrm{V}$ specimens of $3.2 \mathrm{~mm}$ thickness. The equipment used for the tensile tests was an Imada MX2 (Imada Inc., Northbrook, IL, USA) machine equipped with standardized grips. The tension speed was set to $10 \mathrm{~mm} / \mathrm{min}$ while the tests were conducted in room conditions $\left(21^{\circ} \mathrm{C}, 50 \% \mathrm{RH}\right)$. An Imada MX2 machine was also utilized for the flexural tests. The flexural setup was established in the machine according to the ASTM D790-10 international standard. Five specimens of $3.2 \mathrm{~mm}$ thickness and geometry as specified in Figure 2 were tested in three-point bending tests with the chuck speed set at $10 \mathrm{~mm} / \mathrm{min}$. The ASTM D6110-04 international standard was followed for Charpy's notched specimens impact measurements. Five specimens were tested for their impact strength using a Terco MT220 machine (Terco AB, Huddinge, Sweden). Randomly selected specimens were utilized for Vickers microhardness measurements according to the ASTM E384-17 international standard, which was followed for the five measurements conducted on each case of the fabricated nanocomposite material. Microhardness measurements were taken since they are directly related to the material's mechanical response [60]. 

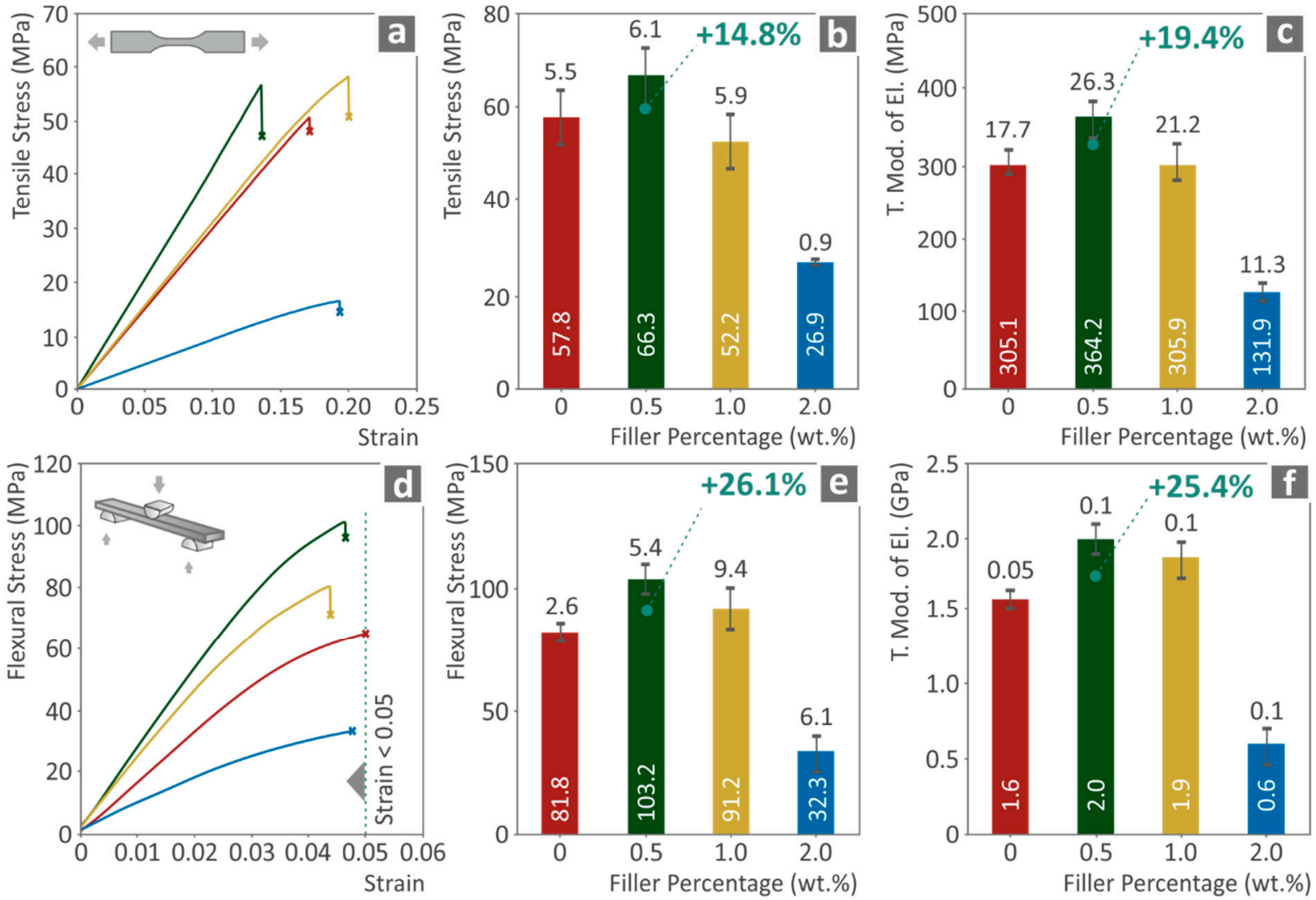

Figure 2. (a) Typical tensile stress (MPa) to strain $(\mathrm{mm} / \mathrm{mm})$ curve, (b) Tensile stress at break (MPa) to filler loading (wt.\%), (c) tensile elastic modulus (MPa) to filler ratio (wt.\%), (d) Typical flexural stress $(\mathrm{MPa})$ to strain $(\mathrm{mm} / \mathrm{mm})$ curve, (e) Flexural stress at break $(\mathrm{MPa})$ or $5.0 \%$ strain -if no break existed- to filler loading (wt.\%), (f) flexural modulus of elasticity (MPa) to filler ratio (wt.\%).

\subsection{Morphological, Thermal, and Antibacterial Analysis}

Scanning electron microscopy (SEM) images were acquired at different magnification levels from the fractured surface of the tensile specimens. A JEOL 6362LV (Jeol Ltd., Norwood MA, USA) apparatus was utilized for this purpose. Samples were randomly selected and sputter-coated with gold $(\mathrm{Au})$ to avoid charging effects. The electron microscope was set in high vacuum mode at $20 \mathrm{kV}$ acceleration voltage. Energy-dispersive X-ray spectroscopy (EDS) analysis was also conducted on the same electronic microscope on non-coated samples from each material to verify the elements in each case.

Micro-scale analysis was conducted on the surface topology of the cured specimens using the atomic force microscopy (AFM) technique with a Microscope Solver P47H Pro (NT-MDT, Moscow, Russia) apparatus. Commercially available silicon cantilevers with a scanning frequency of $1 \mathrm{~Hz}$, cantilever spring constant of $35 \mathrm{~N} / \mathrm{m}$, tip cone angle of $20^{\circ}$, and tip radius of $10 \mathrm{~nm}$ were utilized at a resonant frequency of $300 \mathrm{kHz}$. A part of the 3D printed specimens was also utilized for Thermogravimetric Analysis (TGA) measurements in samples of approximately $10 \mathrm{mg}$. A Perkin Elmer Diamond TGA/DTGA (Perkin Elmer Inc., Waltham, MA, USA) apparatus was used, and the temperature was measured from $40{ }^{\circ} \mathrm{C}$ to $550{ }^{\circ} \mathrm{C}$ with a ramp of $10^{\circ} \mathrm{C} / \mathrm{min}$.

The antibacterial performance of the developed nanocomposites was determined using the agar well diffusion method in a microbiological lab for two (2) different bacteria. Gram-negative Escherichia coli (E. coli) and gram-positive Staphylococcus aureus (S. aureus) bacteria were cultivated in Petri dishes of $85 \mathrm{~mm}$ diameter. Each bacterium was cultivated with a specific growth material in different Petri dishes. Specimens of $12.7 \mathrm{~mm}$ diameter 
and height of $5.00 \mathrm{~mm}$ were placed in each petri dish. Petri dishes were placed in an oven at $37^{\circ} \mathrm{C}$ for a period of $24 \mathrm{~h}$ targeting the optimized diffusion of antimicrobial agents in the agar and inhibiting germination and growth of the test microorganism. Subsequently, the inhibition zones (IZ) of 3D printed specimens were measured peripherally using optical equipment.

\section{Results}

\subsection{Mechanical Performance Analysis}

Figure $2 \mathrm{a}-\mathrm{c}$ present the tensile testing results for the fabricated nanocomposites compared to the clear resin utilized as matrix material. It is found that the presence of Cuprous Oxide in the nanocomposite affects the tensile behavior of the matrix material. Maximum enhancement was measured in the case of $\mathrm{SC} \mathrm{Cu}_{2} \mathrm{O} 0.5 \mathrm{wt} . \%$ nanocomposite, with the tensile stress at break measured to be approximately $15.0 \%$ higher than neat SC (Figure $2 b$ ), and the corresponding tensile modulus of elasticity was increased approximately $20.0 \%$ (Figure 2c). Higher filler loadings exhibited degraded performance, which was attributed to increased $\mathrm{Cu}_{2} \mathrm{O}$ presence in the nanocomposites and a plausible difficulty in photopolymerization, resulting in not completely photopolymerized specimens.

Figure $2 \mathrm{~d}-\mathrm{f}$ present the corresponding results from the flexural tests conducted on the specimens. A similar tensile behavior trend was observed in the flexural stress analysis. A stiffening effect was observed for all fabricated nanocomposites, which was a result of the introduction of metal oxides into the materials. The flexural stress at break and flexural modulus of elasticity were measured enhanced by approximately $25.0 \%$ (Figure 2e) compared to neat SC resin. Deterioration over $0.5 \mathrm{wt}$ \% filler ratio was also presented. Such performance is attributed to the increased filler loading as described above.

In Figure 3, a comparative analysis is depicted for the tensile and the flexural toughness $\left(\mathrm{MJ} / \mathrm{m}^{3}\right)$, i.e., the integral of the corresponding stress-strain curves of all tested specimens. This analysis is related to the absorbed energy from each trial until breakage occurred or $5.0 \%$ strain for flexural tests when no break occurred, following the corresponding standard instructions. Based on the results presented previously, the calculated toughness for tensile and flexural tests exhibits a similar performance for the studied nanocomposites. Low filling ratios enable the potential to create plausible stronger interface bonds between photopolymerized polymeric chains of SC resin with filler nanoparticles. Such interface fusion enhances the stiffness of the material, followed by an increase in the measured stresses and the ability to absorb more energy during deformation. The mechanism that creates obstacles in higher filling loadings in nanocomposites will be further analyzed in the Section 4.
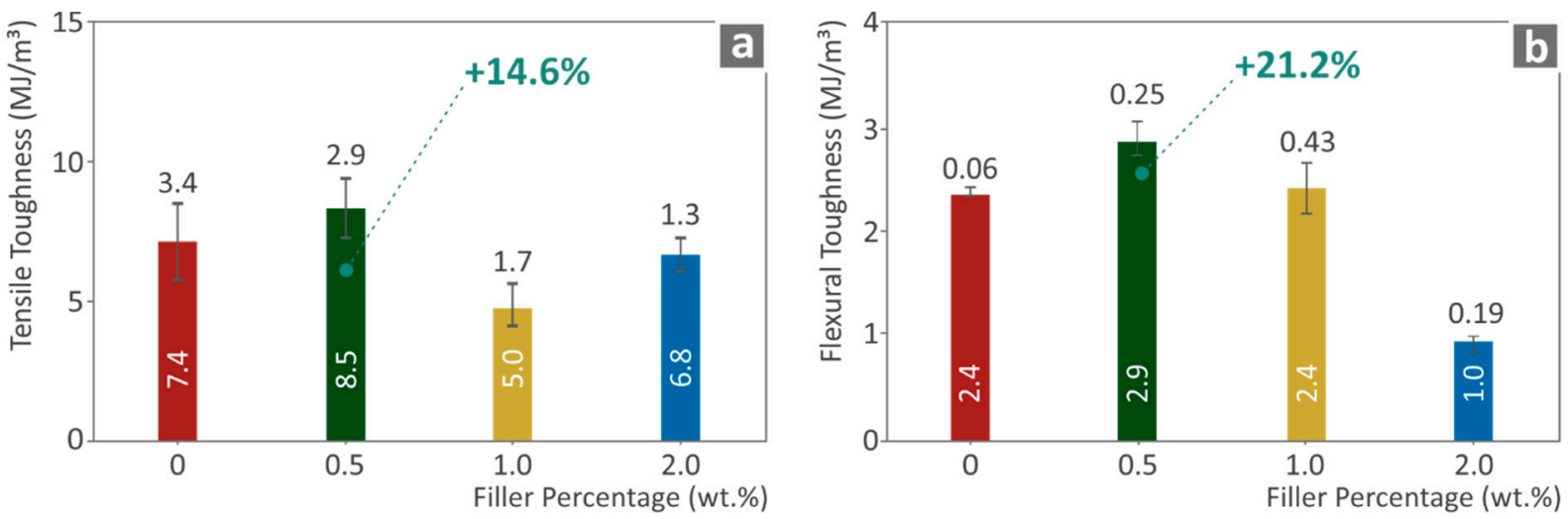

Figure 3. Cont. 

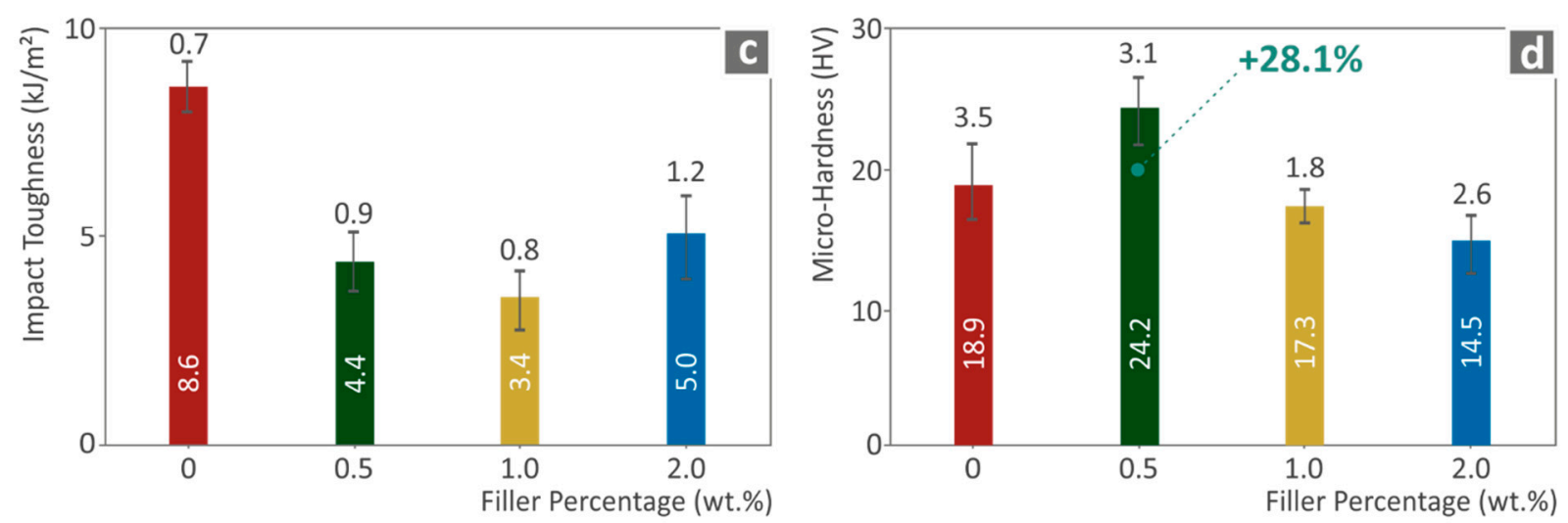

Figure 3. (a) Average tensile toughness $\left(\mathrm{MJ} / \mathrm{m}^{3}\right.$ ) to filler loading (wt.\%), (b) Average flexural toughness $\left(\mathrm{MJ} / \mathrm{m}^{3}\right.$ ) to filler ratios (wt.\%), (c) Charpy's notched impact toughness $\left(\mathrm{kJ} / \mathrm{m}^{2}\right)$ to filler loadings (wt.\%), (d) Vickers microhardness (HV) to filler ratios (wt.\%).

Finally, impact toughness and Vickers microhardness tests results are shown in Figure 3c. Impact tests did not follow the same trend as the remaining mechanical tests, exhibiting an intense degradation in the ability to absorb impact energy. Generally, SLAutilized resins perform in a non-ductile manner. This high stiffening behavior worsens the ability to enhance the impact property. In addition, metal oxides are also materials with low to almost non-existent ductility, which results in further enhancement of stiffness, as shown above. Vickers microhardness follows the already presented performance of the nanocomposites (Figure 3d). Following the quasi-static tests, the specimen surface behaved accordingly to the internal structure performance.

\subsection{Thermal, Morphological, and Antibacterial Analysis \\ 3.2.1. Thermal Analysis}

Thermogravimetric analysis was conducted on samples acquired from 3D printed specimens. The results are shown in Figure 4. In Figure 4a, it can be observed that the addition of filler to each nanocomposite is in agreement with the weight, as the remnants agree with the corresponding loading. It should be mentioned that even pure SC resin had not completely burned at the highest achieved temperature of $550{ }^{\circ} \mathrm{C}$, and as a result, the existence of the filler in the nanocomposite is a qualitative assumption and not an exact measured one. In Figure $4 b$, in which the weight loss rate is presented, it is shown that the addition of $\mathrm{Cu}_{2} \mathrm{O}$ over $0.5 \mathrm{wt} . \%$ in the nanocomposite is intensively changing the thermal performance of the fabricated nanocomposite materials. Thus, such an effect enhances the mechanical deterioration behavior, as the thermal degradation of $1.0 \mathrm{wt} . \%$ and $2.0 \mathrm{wt} . \%$ nanocomposites is plausibly attributed to a not totally, or bad-quality photopolymerization procedure, as for the filler existence in the nanocomposite.

\subsubsection{Morphological Analysis}

For a complete view of this study's process, morphology analysis was conducted utilizing SEM on the side and fractal surface of tensile specimens. Figure 5 present the side surfaces of the specimens at two magnification levels. The side surface of the SC resin specimen exhibits a smooth morphology; the layering is still visible and is in coherence with the 3D printing settings. The fusion quality of the layers is observed to be good. A similar morphology is observed for the nanocomposite $\mathrm{SC} \mathrm{Cu}_{2} \mathrm{O} 0.5 \mathrm{wt} . \%$, while for the higher filler's concentration, nanocomposite fusion quality shows degradation. Additionally, the implications of plausible agglomerations are shown for these nanocomposites. These observations enhance the assumption that there were difficulties in the photopolymerization process for the nanocomposites with $1.0 \mathrm{wt} . \%$ and $2.0 \mathrm{wt} . \%$ loadings.

Figure 6 presents SEM images from the fracture area of the tensile specimens. Following the side surface analysis, the fracture area provides more information and proof of the 
deteriorated processing at higher filler ratios in the fabricated nanocomposites. Plausible agglomerations are visible, while the total morphology of the fractal area in the two higher filled nanocomposites exhibited slight voids, which probably occurred due to the pure photopolymerization of the matrix SC resin. The fracture area morphology also exhibits a stiffening effect due to the introduction of Cuprous Oxide in the nanocomposites. The traveling direction of the break that occurred during the tensile test is clear in the case of pure $\mathrm{SC}$ and $\mathrm{SC} \mathrm{Cu}_{2} \mathrm{O} 0.5 \mathrm{wt} . \%$. A slight decrease in the ductility of the resin was observed even at $0.5 \mathrm{wt} . \%$ nanocomposites. The brittleness effect occurred due to the metal oxide presence, which is visible in the fractal areas of higher filler loadings images.
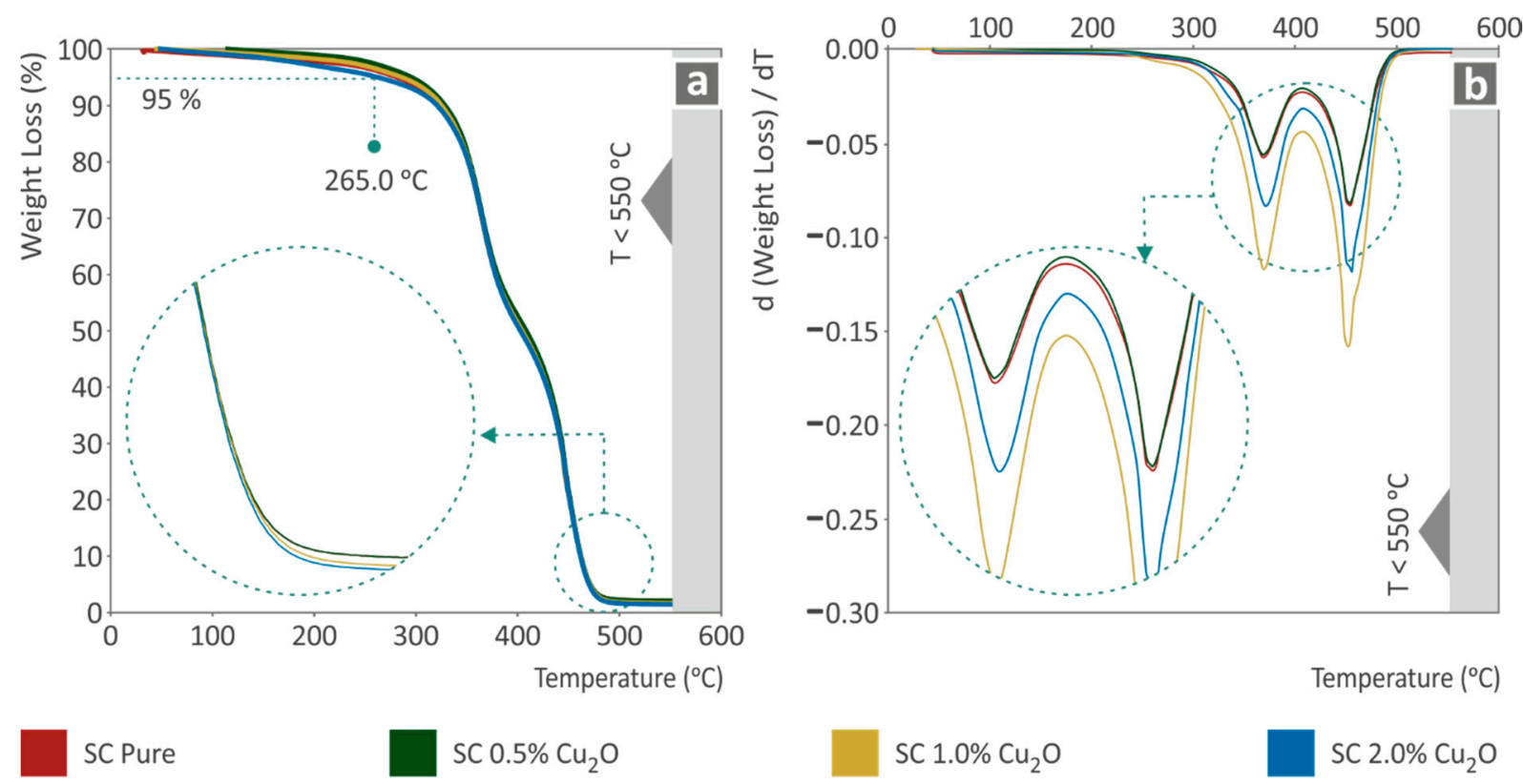

Figure 4. (a) Sample's weight $(\%)$ to temperature $\left({ }^{\circ} \mathrm{C}\right)$, (b) weight loss rate $(\mathrm{mg} / \mathrm{mg})$ to temperature $\left({ }^{\circ} \mathrm{C}\right)$.
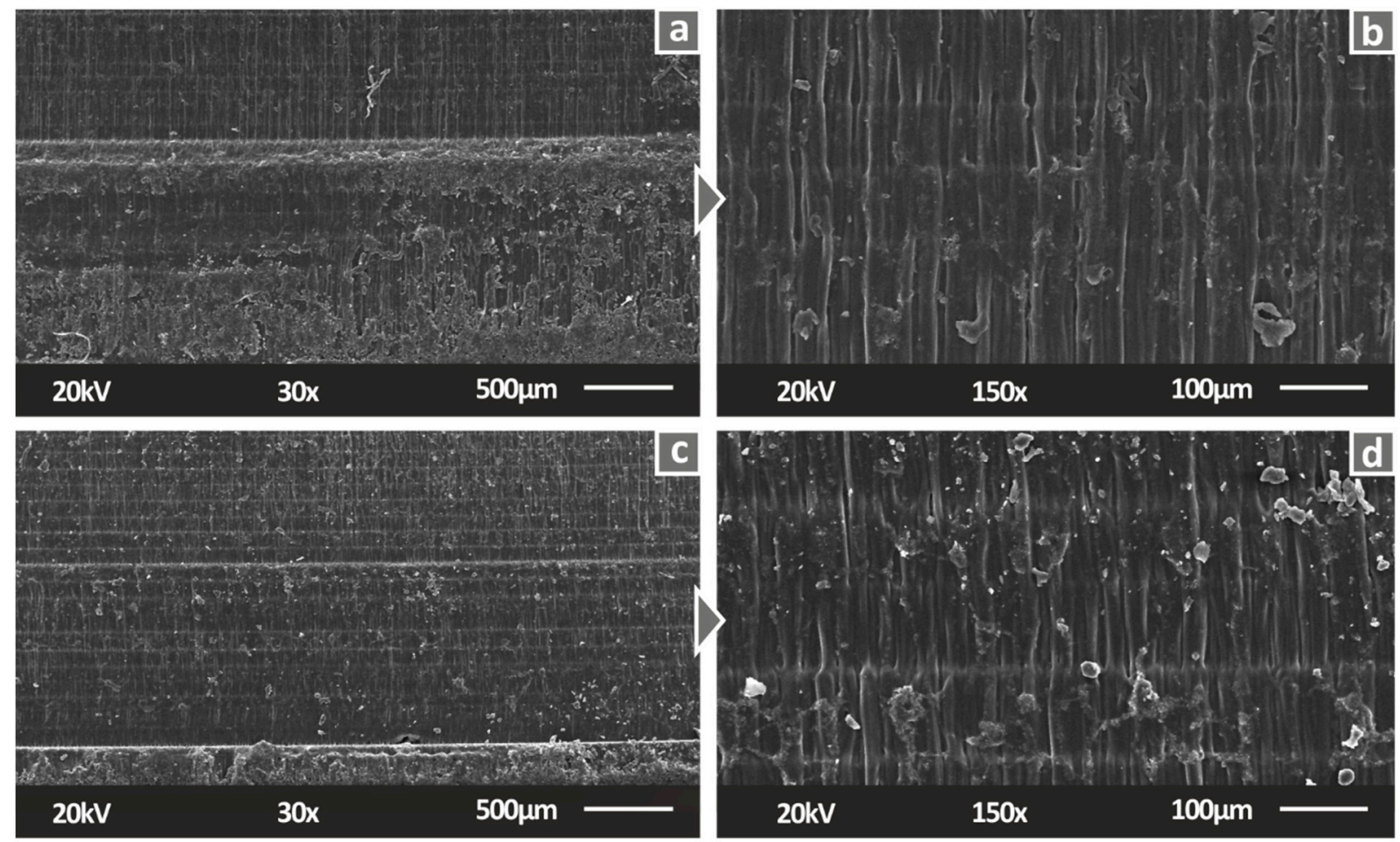

Figure 5. Cont. 

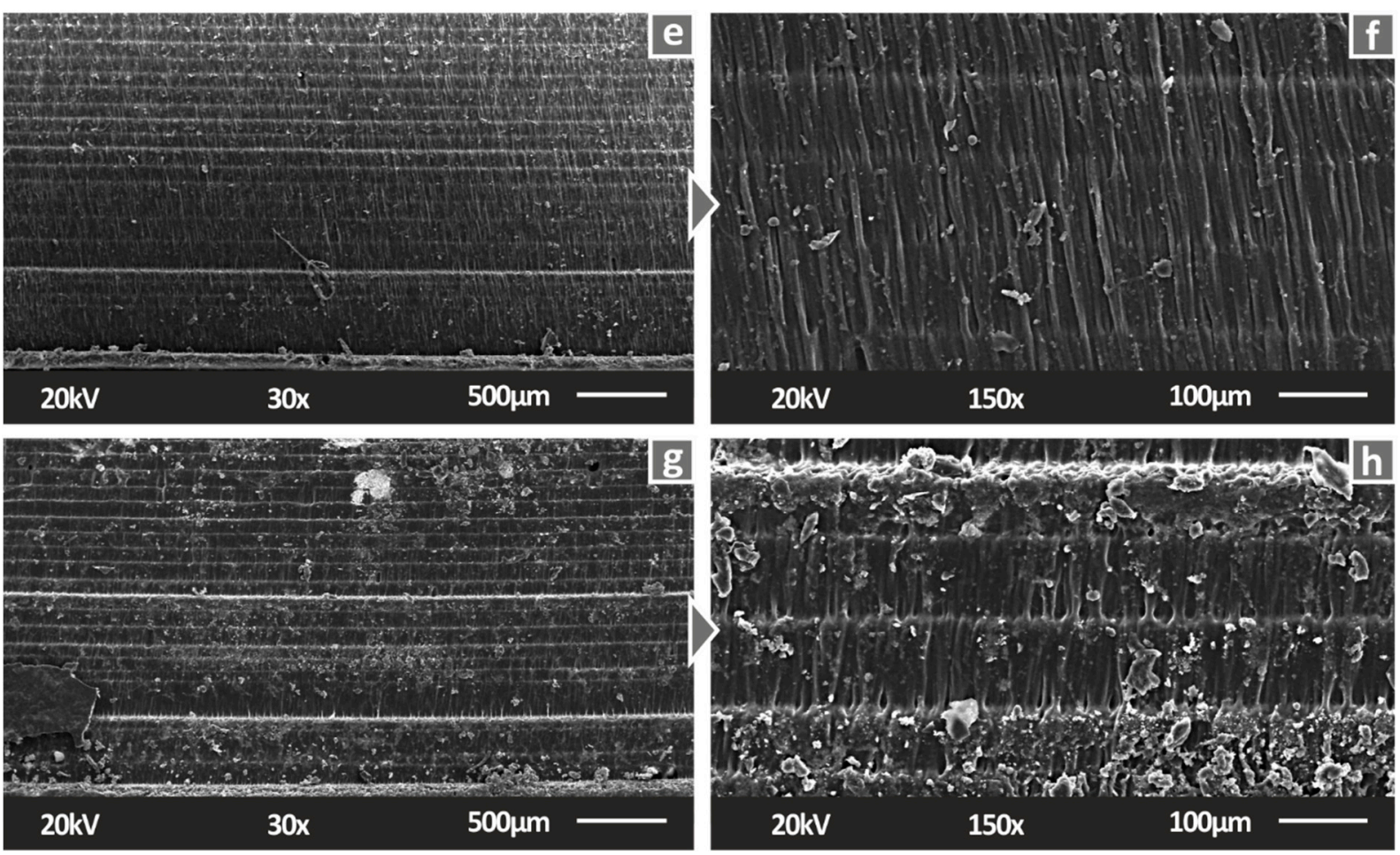

Figure 5. Side surface of tensile specimens in $30 \times$ magnification for (a) Pure SC, (c) SC Cu $2 \mathrm{O} 0.5$ wt.\%, (e) $\mathrm{SC} \mathrm{Cu}_{2} \mathrm{O} 1.0$ wt. $\%$, (g) SC Cu $2 \mathrm{O} 2.0$ wt. $\%$, same surfaces in $150 \times$ magnification for (b) Pure SC, (d) $\mathrm{SC} \mathrm{Cu}_{2} \mathrm{O} 0.5 \mathrm{wt} . \%$, (f) $\mathrm{SC} \mathrm{Cu} \mathrm{Cu}_{2} 1.0 \mathrm{wt} . \%$, (h) $\mathrm{SC} \mathrm{Cu}_{2} \mathrm{O} 2.0 \mathrm{wt} . \%$.
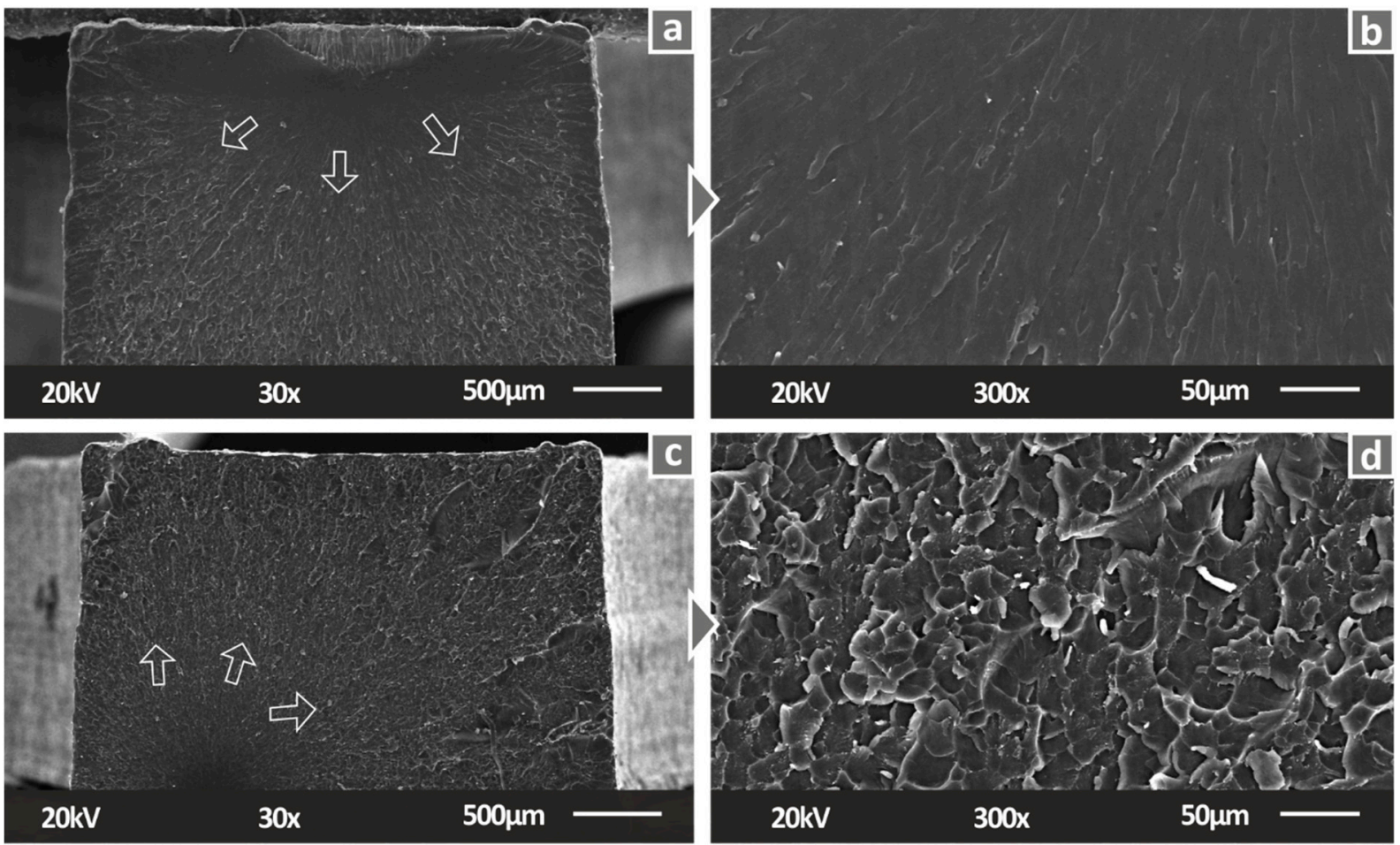

Figure 6. Cont. 

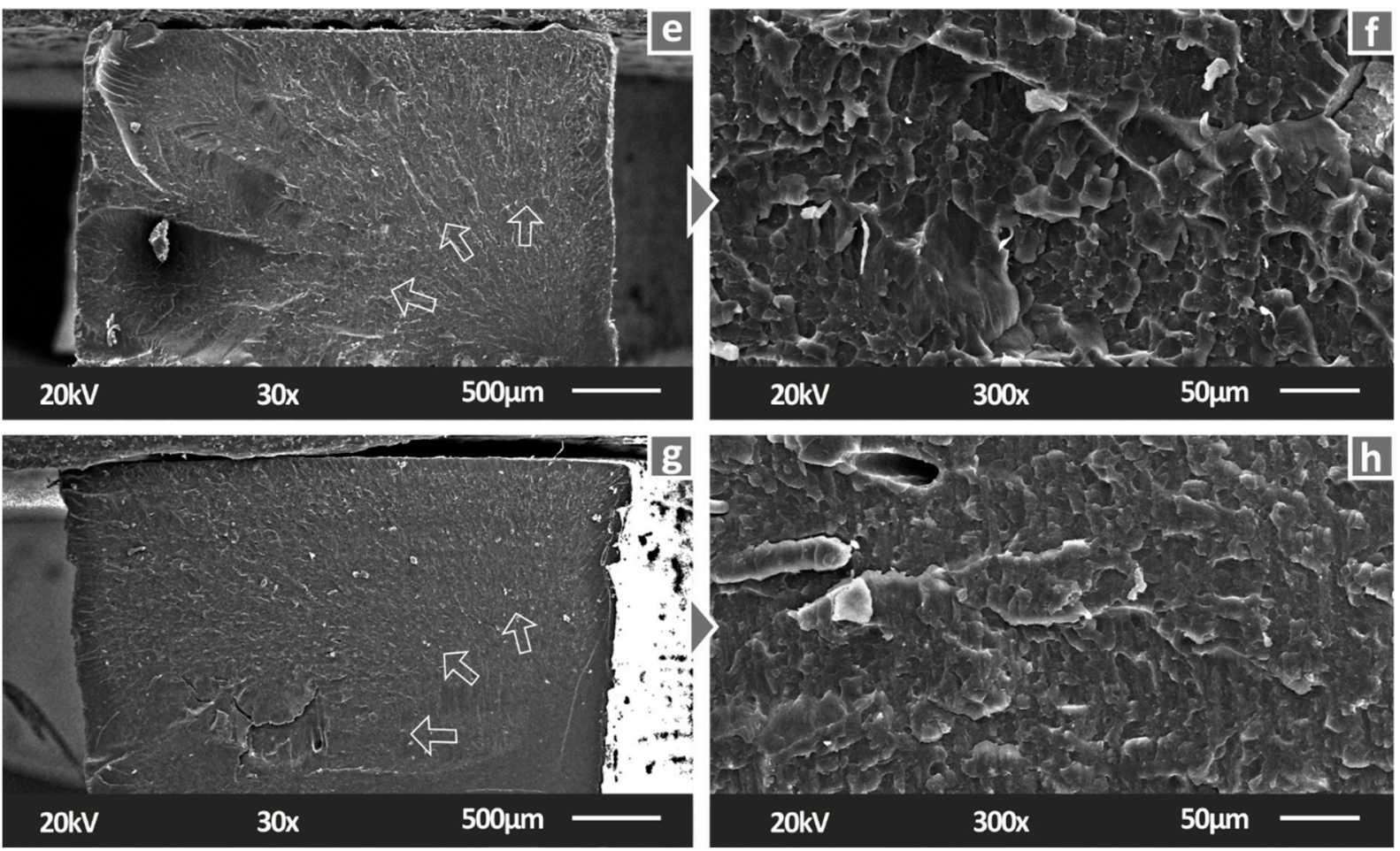

Figure 6. Fracture surface of tensile specimens in $30 \times$ magnification for (a) Pure SC, (c) $\mathrm{SC} \mathrm{Cu}_{2} \mathrm{O}$ 0.5 wt.\%, (e) SC Cu $2 \mathrm{O} 1.0$ wt.\%, (g) SC $\mathrm{Cu}_{2} \mathrm{O} 2.0$ wt.\%, same surfaces in $300 \times$ magnification for (b) Pure SC, (d) SC Cu $2 \mathrm{O} 0.5$ wt.\%, (f) SC Cu $2 \mathrm{O} 1.0$ wt.\%, (h) SC $\mathrm{Cu}_{2} \mathrm{O} 2.0$ wt.\%.

Higher magnification captures were taken in the fractal area and EDS analysis on the specimens' surface. Figure 7 presents images and EDS results for the nanocomposites fabricated for the current study. The presence of $\mathrm{Cu}$ in the EDS graphs, because of the addition of Cuprous Oxide, is expected in each fabricated nanocomposite, with the peaks verifying the good dispersion of the filler in all cases.

Finally, the morphology and the quality of the procedure were also evaluated with atomic force microscopy (AFM) analysis on the 3D printed specimens' surfaces of all tested materials. The surface topology of higher filled nanocomposites presents a vigorous roughness increase, plausibly attributed to slight agglomerations created. The $\mathrm{SC} \mathrm{Cu}_{2} \mathrm{O}$ $0.5 \mathrm{wt} . \%$ nanocomposite's surface roughness has a fine quality finishing, with low differences, implying that nanoparticles had dispersed fine, and the polymerization process faced no difficulties.

\subsubsection{Nanocomposites Biocidal Performance}

To mimic HDPs functionalities in the nanocomposites developed, biocidal characteristics must be induced, and to achieve that, the Cuprous Oxide filler's properties were exploited in the study. The antibacterial performance of the prepared nanocomposites was investigated using the agar well diffusion method, and the results for the two tested bacteria are presented in the following figures. Images after $24 \mathrm{~h}$ of cultivation in Petri dishes of gram-negative E. coli are displayed in Figure 8. The antibacterial properties of Cuprous Oxide were introduced in the fabricated nanocomposites. In particular, the increase in Cuprous Oxide concentration in the matrix increased in the inhibition zone. It should be mentioned that the SC resin did not exhibit any antibacterial performance, as expected, which creates a great potential for Cuprous Oxide addition in resin matrices.

Similar behavior was observed in the case of the gram-positive S. aureus testing case. As shown in Figure 9, antibacterial activity was introduced in the nanocomposites by the addition of $\mathrm{Cu}_{2} \mathrm{O}$ as a filler in the SC resin. Indeed, in the case of $0.5 \mathrm{wt} . \%$ filler ratio, the inhibition zone against $S$. Aureus was further increased compared to the corresponding 
E. Coli. Following a similar trend to the E. coli bacterium behavior, an increase in the Cuprous Oxide presence increased the inhibition zone to $S$. aureus. As a result, the optimization process of the antibacterial behavior is only impeded by the processability of the materials, which is mainly focused on the effective photopolymerization and the reduction of agglomeration effects.
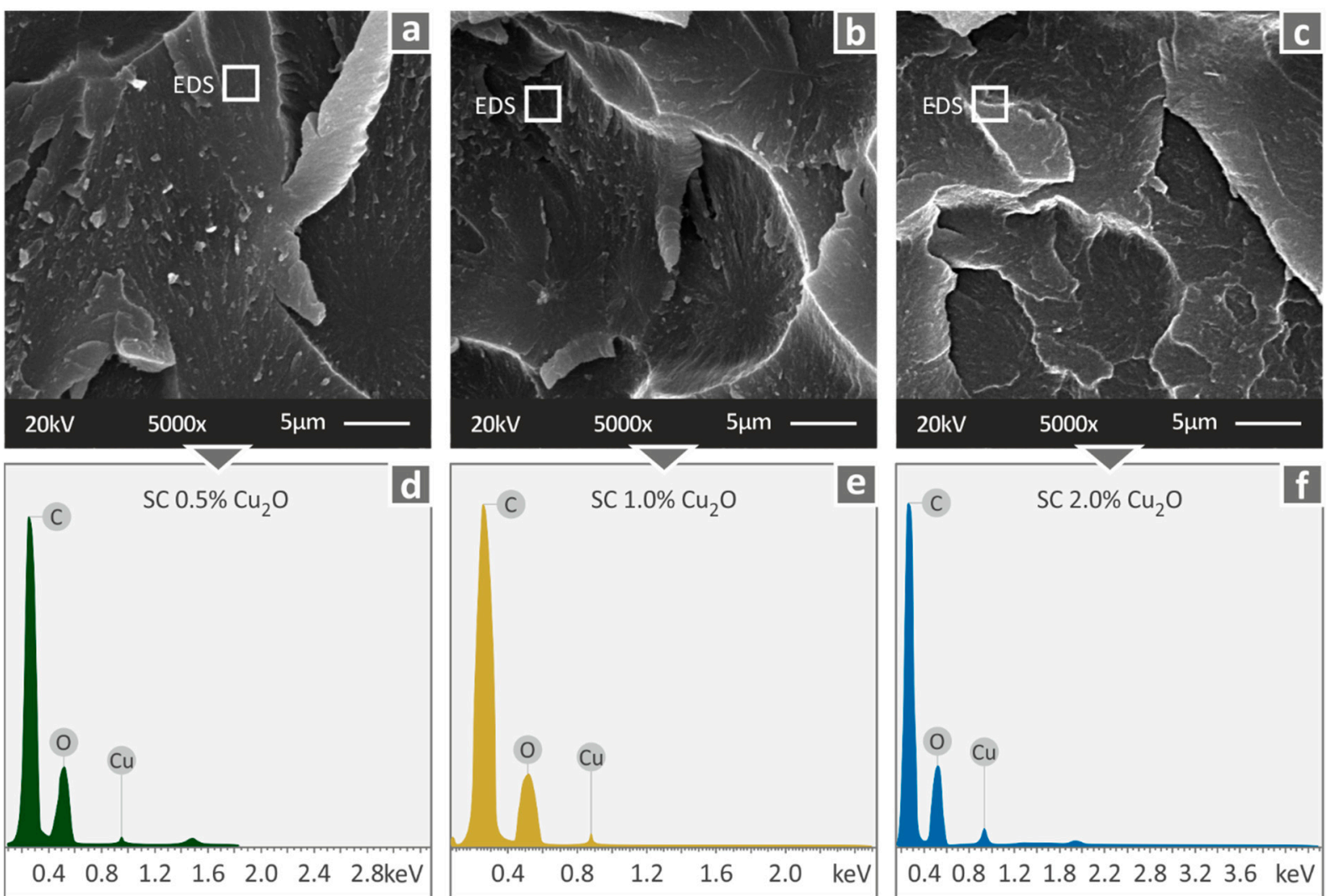

$\mathrm{SC} 0.5 \% \mathrm{Cu}_{2} \mathrm{O}$

Figure 7. Fracture area high magnification captures at $5000 \times$ level and the corresponding EDS

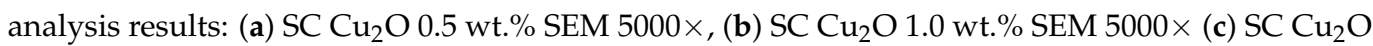
2.0 wt. $\%$ SEM $5000 \times$ (d) SC Cu 200.5 wt.\% EDS graph (e) SC $\mathrm{Cu}_{2} \mathrm{O} 1.0$ wt.\% EDS graph, (f) $\mathrm{SC} \mathrm{Cu}_{2} \mathrm{O}$ 2.0 wt. $\%$ EDS graph.
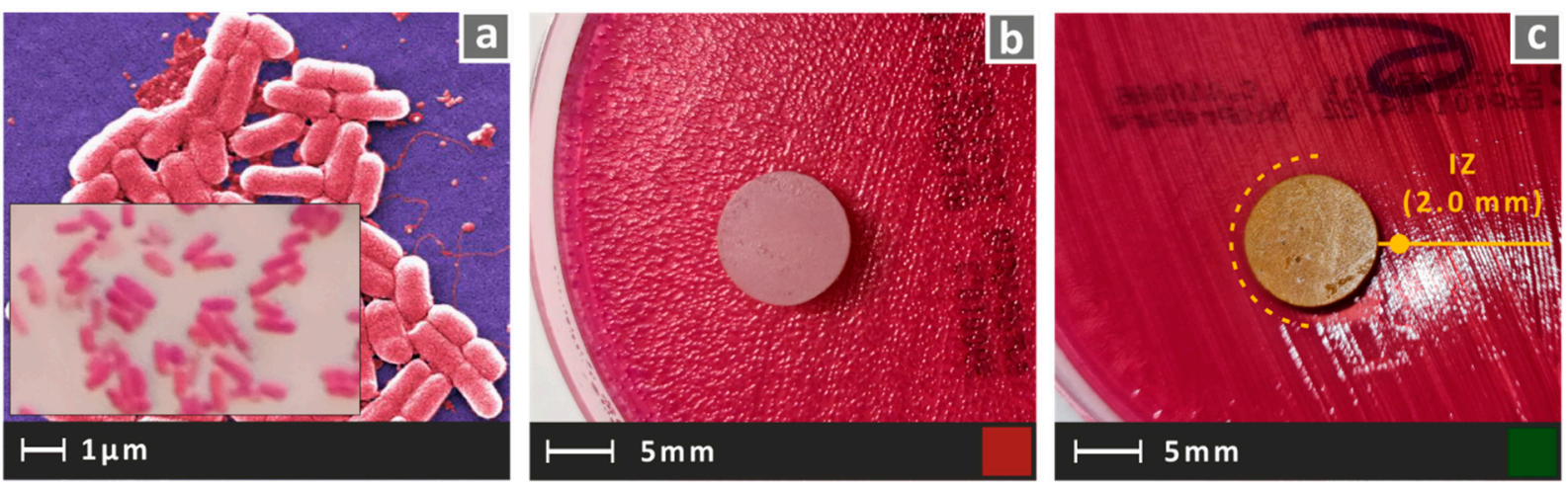

Figure 8. Cont. 

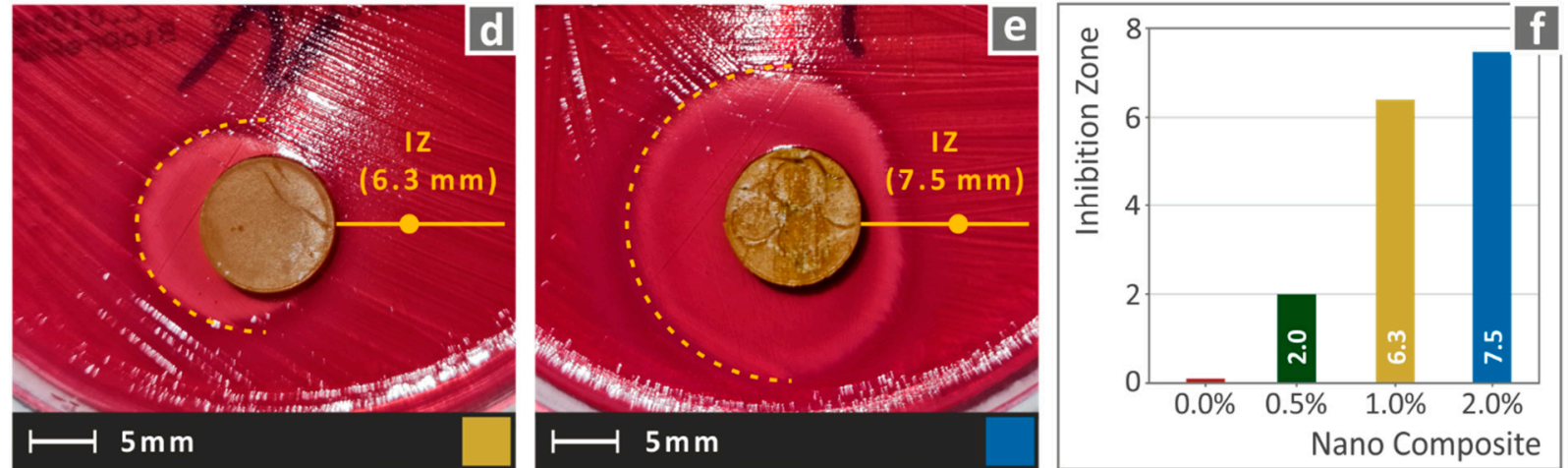

SC Pure
$\mathrm{SC} 0.5 \% \mathrm{Cu}_{2} \mathrm{O}$
SC $1.0 \% \mathrm{Cu}_{2} \mathrm{O}$
$\mathrm{SC} 2.0 \% \mathrm{Cu}_{2} \mathrm{O}$

Figure 8. (a) typical E. Coli morphology, (b-e) Vertical captures after $24 \mathrm{~h}$ cultivation of tested specimen in a petri dish for each corresponding tested material, (f) Comparative graph of the measured inhibition zones to filler loading (wt.\%).
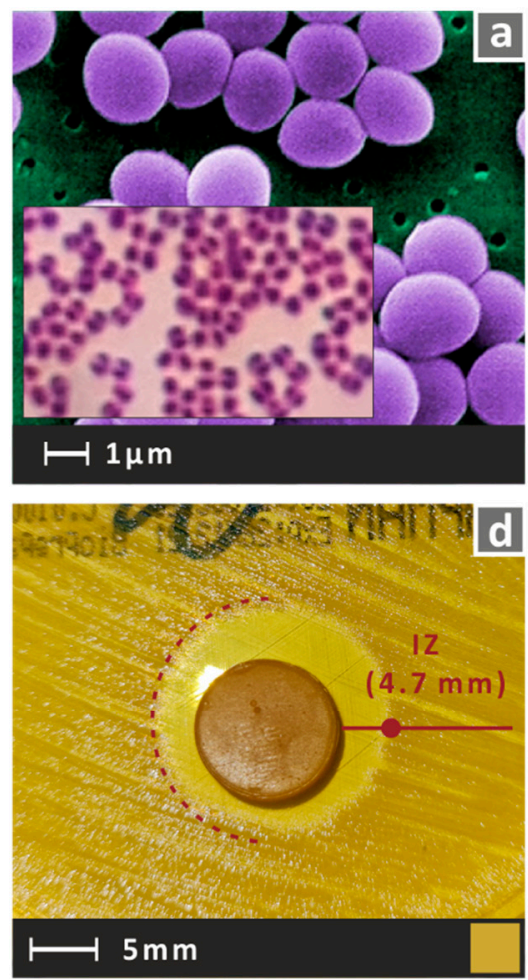

SC Pure
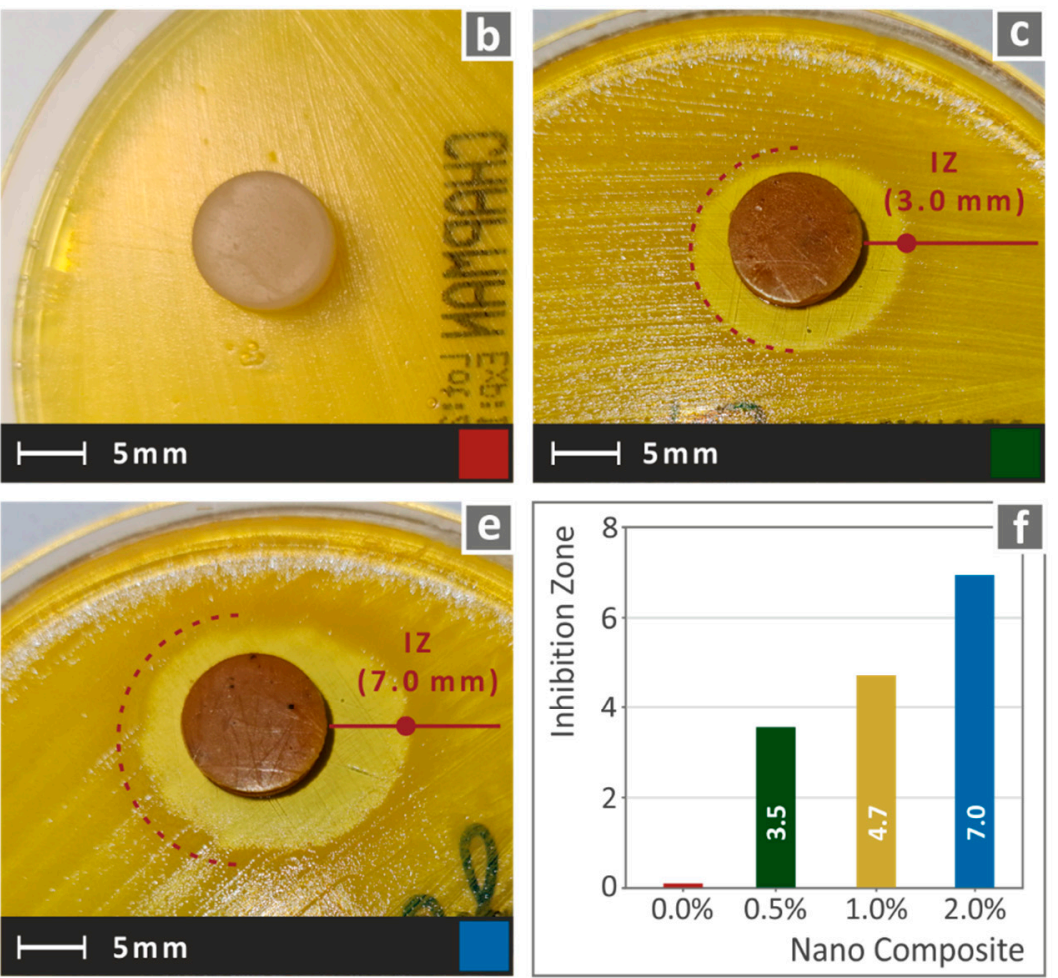

SC $1.0 \% \mathrm{Cu}_{2} \mathrm{O}$

$\mathrm{SC} 2.0 \% \mathrm{Cu}_{2} \mathrm{O}$

Figure 9. (a) typical S. aureus morphology, (b-e) Vertical captures after 24 h cultivation of tested specimen in a petri dish for each corresponding tested material, (f) Comparative graph of the measured inhibition zones to filler loading (wt.\%).

\section{Discussion}

In this work affordable materials suitable for SLA 3D printing, mimicking HDPs performance were prepared and fully characterized. Such materials with antibacterial performance for medical purposes are developed for the design of medical tools, antibacterial surfaces, etc., that prevent bacteria germination and growth. These materials, in most cases, are not designed for prolonged contact with living organisms or to be introduced in the human body since malicious tissue interaction with the composite or other side effects 
that affect the cells are possible. For this reason, cytotoxicity studies are also required in these cases, and the safety of materials for in vivo use should be ensured. Studying the in vivo antibacterial efficacy of the developed materials of the study was not in the scopes of the study.

The purpose of this work was to introduce antibacterial properties to an SLA resin by employing a low-cost antibacterial filler and common laboratory tools. The principle of the process followed for the preparation of the nanocomposites is based on high-shear forces for the mixing process of the filler with the matrix material. Mechanical, morphological, thermal, and antibacterial analyses were conducted on SLA 3D printed specimens of SC resin and Cuprous Oxide-filled nanocomposites. Mechanical analysis results indicated that the addition of $\mathrm{Cu}_{2} \mathrm{O}$ at a low filling ratio enhanced the tensile and flexural performance of the SC resin. A higher filler concentration exhibited a sudden degraded mechanical performance, as the fabricated SC $\mathrm{Cu}_{2} \mathrm{O} 1.0 \mathrm{wt} . \%$ and $2.0 \mathrm{wt} . \%$ nanocomposites performed over $50 \%$ lower than the lower filler loading both in tensile and in flexural stress tests. The SLA 3D printing process induces a laser beam in a specific laser spot (150 microns to the utilized 3D printer) to initiate the polymerization process to the photosensitive resin. Nanoparticles induced in the SC resin matrix could create diffusion effects, especially in the case of high concentrations, where the agglomeration effect could plausibly occur at the higher filler loadings. Low filler addition enables nanoparticles to disperse in the matrix most finely, reducing even the possibility of slight agglomeration. The $0.5 \mathrm{wt} \%$ loading exhibited overall the more enhanced mechanical response, with the tensile strength being $26.1 \%$ higher than the matrix material, the tensile elastic modulus $25.4 \%$ higher, indicating a stiffer behavior of the material with the addition of the filler, flexural strength was increased $14.6 \%$, and flexural modulus of elasticity was also $21.2 \%$ higher than the matrix material, verifying the stiffer behavior of the nanocomposite in this test. Even at this low filler loading, the nanocomposite exhibited antibacterial performance for the two bacteria studied, showing potential for multi-functional performance in this nanocomposite. The process followed, employing common laboratory equipment and a rather low-cost filler with antibacterial properties, introduced a nanocomposite with low filler loading of $0.5 \mathrm{wt}$.\% and optimum performance, which has obvious advantages. Apart from the improved mechanical performance and the antibacterial response, low filler loading is easier to process, and the overall cost for the preparation of the nanocomposite is not significantly increased when compared to the cost of the matrix material. More specifically, the additional cost for the filler at this loading is about $1.5 \%$ of the materials cost, with is rather negligible, although additional preparation costs should be considered, too.

In the case of higher filled nanocomposites, as tested for the current study, nanoparticles could create agglomerations. Even slight agglomerations may not introduce processability difficulties in other AM techniques; in the case of the SLA process, the micro-sized laser spot and the locally introduced light energy for the polymerization procedure may cause serious damage to the 3D printing quality. Cuprous Oxide is a metal oxide that is vulnerable to agglomeration effects. Even though the agglomerations conducted on high-concentration nanocomposites were of low intensity, the studied SLA technology was critically affected. The degraded performance over $0.5 \mathrm{wt}$ \% filled nanocomposites is plausibly attributed to such effects. Diffusion in the local range of agglomeration areas has forced the matrix resin material to not fully polymerize, degrading the total fusion of the nanocomposite.

The SLA process requires extra photopolymerization processing after washing in IPA dilution, which enhances the properties of the 3D printed material. Low photopolymerized nanocomposites with higher Cuprous Oxide loadings did not have the opportunity to upcycle during the curing process. This was a result of the washing process, during which uncured areas around the nanoparticles were removed from the IPA bath. The processing followed during the current study, the utilized materials, and the corresponding equipment used, provided the ability to fabricate nanocomposites with enhanced mechanical, thermal, and antibacterial performance. Additionally, threshold points were plausibly obtained 
after a comparative analysis of sufficient filler loadings. The addition of Cuprous Oxide nanoparticles in low concentrations, such as these of $0.5 \mathrm{wt} . \%$, enabled the photosensitive SLA resin and enhanced its mechanical performance. Antibacterial performance was also sufficient in the nanocomposites, while higher Cuprous Oxide ratios could create even improved inhibition zones. An optimization study could be conducted as future work for the 3D printing settings to filler loadings to achieve the highest possible antibacterial performance without compromising the photopolymerization procedure, resulting in excellent mechanical behavior.

\section{Conclusions}

For the current study, a rather simple fabrication method was used to prepare nanocomposite materials with bacteria inhibiting properties for the SLA 3D printing process. More specifically, the effect of Cuprous Oxide addition in SLA-utilized resin matrix materials was investigated for the study. A common, rather low-cost, commercially available resin was utilized as a matrix material, and Cuprous Oxide nanoparticles were induced at different filling ratios. SLA 3D printing technology was utilized for the fabrication of the specimens, and international standards were followed for the mechanical, morphological, thermal, and antibacterial properties investigation on the prepared nanocomposites. The results indicated that the addition of filler at low ratios, such as these of $0.5 \mathrm{wt} . \%$, could provide a significant advantage to SLA resins for implementation in engineering and medical applications. The antibacterial performance of the prepared nanocomposites was verified with the agar well diffusion method, while, at the same time, the introduction of the filler enhanced the mechanical response of the materials when compared with the matrix material of the study. These results revealed the high potential of these materials as multi-functional materials in applications requiring the inhibition of bacteria populations, which is of great interest in medicine and other fields [61].

The processing of such nanocomposites does not require procedures of high complexity, while the optimization of 3D printing settings consists of easy steps. Generally, the addition of Cuprous Oxide at concentrations higher than $0.5 \mathrm{wt}$ \% ratios introduced slight agglomerations and plausibly low-quality polymerization. In contrast, antibacterial properties, which are significant for medical applications, exhibited an increased rate following the increased presence of Cuprous Oxide in each nanocomposite. Finally, this enables the potential of future studies for optimizing the process of the introduction of such nanoparticles in resin matrices to achieve optimum antibacterial performance in combination with ease of processing and enhanced mechanical behavior.

Author Contributions: Conceptualization, N.V. and E.V.; methodology, M.P.; software, N.M., J.D.K. and C.N.D.; validation, N.V., C.N.D., J.D.K. and M.P.; formal analysis, M.P. and J.D.K.; investigation, E.V. and C.N.D.; resources, N.V. and S.P.; data curation, N.M. and S.P.; writing-original draft preparation. E.V.; writing-review and editing, M.P.; visualization, N.V., N.M. and S.P.; supervision, N.V.; project administration, M.P.; funding acquisition, N.V. All authors have read and agreed to the published version of the manuscript.

Funding: This research received no external funding.

Institutional Review Board Statement: Not applicable.

Informed Consent Statement: Not applicable.

Data Availability Statement: The data presented in this study are available upon request from the corresponding author.

Acknowledgments: The authors would like to thank Aleka Manousaki from the Institute of Electronic Structure and Laser of the Foundation for Research and Technology, Hellas (IESL-FORTH), for taking the SEM images presented in this work.

Conflicts of Interest: The authors declare no conflict of interest. 


\section{References}

1. Chee, E.; Brown, A.C. Biomimetic antimicrobial material strategies for combating antibiotic-resistant bacteria. Biomater. Sci. 2020, 8, 1089-1100. [CrossRef]

2. Raffi, M.; Mehrwan, S.; Bhatti, T.M.; Akhter, J.I.; Hameed, A.; Yawar, W.; Ul Hasan, M.M. Investigations into the antibacterial behavior of copper nanoparticles against Escherichia coli. Ann. Microbiol. 2010, 60, 75-80. [CrossRef]

3. Ergene, C.; Yasuhara, K.; Palermo, E.F. Biomimetic antimicrobial polymers: Recent advances in molecular design. Polym. Chem. 2018, 9, 2407-2427. [CrossRef]

4. Slavin, Y.N.; Asnis, J.; Häfeli, U.O.; Bach, H. Metal nanoparticles: Understanding the mechanisms behind antibacterial activity. J. Nanobiotechnol. 2017, 15, 1-20. [CrossRef] [PubMed]

5. Chatterjee, A.K.; Chakraborty, R.; Basu, T. Mechanism of antibacterial activity of copper nanoparticles. Nanotechnology 2014, 25, 135101. [CrossRef]

6. Liu, J.; Wu, D.; Zhu, N.; Wu, Y.; Li, G. Antibacterial mechanisms and applications of metal-organic frameworks and their derived nanomaterials. Trends Food Sci. Technol. 2021, 109, 413-434. [CrossRef]

7. Savolainen, J.; Collan, M. How Additive Manufacturing Technology Changes Business Models?-Review of Literature. Addit. Manuf. 2020, 32, 101070. [CrossRef]

8. Vairis, A.; Petousis, M.; Vidakis, N.; Savvakis, K. On the Strain Rate Sensitivity of Abs and Abs Plus Fused Deposition Modeling Parts. J. Mater. Eng. Perform. 2016, 25, 3558-3565. [CrossRef]

9. Dilberoglu, U.M.; Gharehpapagh, B.; Yaman, U.; Dolen, M. The Role of Additive Manufacturing in the Era of Industry 4.0 Procedia Manuf. 2017, 11, 545-554. [CrossRef]

10. Valvez, S.; Santos, P.; Parente, J.M.; Silva, M.P.; Reis, P.N.B. 3D Printed Continuous Carbon Fiber Reinforced PLA Composites: A Short Review. Procedia Struct. Integr. 2020, 25, 394-399. [CrossRef]

11. Chinthavali, M. 3D Printing Technology for Automotive Applications. In Proceedings of the 3D-PEIM 2016-2016 International Symposium on 3D Power Electronics Integration and Manufacturing, Raleigh, CA, USA, 21-23 June 2016.

12. Yelamanchi, B.; Mummareddy, B.; Santiago, C.C.; Ojoawo, B.; Metsger, K.; Helfferich, B.; Zapka, J.; Sillani, F.; MacDonald, E.; Cortes, P. Mechanical and Fatigue Performance of Pressurized Vessels Fabricated with Multi Jet Fusion ${ }^{\mathrm{TM}}$ for Automotive Applications. Addit. Manuf. 2021, 44, 102048. [CrossRef]

13. Tzounis, L.; Bangeas, P.I.; Exadaktylos, A.; Petousis, M.; Vidakis, N. Three-Dimensional Printed Polylactic Acid (PLA) Surgical Retractors with Sonochemically Immobilized Silver Nanoparticles: The next Generation of Low-Cost Antimicrobial Surgery Equipment. Nanomaterials 2020, 10, 985. [CrossRef]

14. Valentine, A.D.; Busbee, T.A.; Boley, J.W.; Raney, J.R.; Chortos, A.; Kotikian, A.; Berrigan, J.D.; Durstock, M.F.; Lewis, J.A. Hybrid 3D Printing of Soft Electronics. Adv. Mater. 2017, 29, 1703817. [CrossRef] [PubMed]

15. Vidakis, N.; Maniadi, A.; Petousis, M.; Vamvakaki, M.; Kenanakis, G.; Koudoumas, E. Mechanical and Electrical Properties Investigation of 3D-Printed Acrylonitrile-Butadiene-Styrene Graphene and Carbon Nanocomposites. J. Mater. Eng. Perform. 2020, 29, 1909-1918. [CrossRef]

16. Vidakis, N.; Petousis, M.; Savvakis, K.; Maniadi, A.; Koudoumas, E. A comprehensive investigation of the mechanical behavior and the dielectrics of pure polylactic acid (PLA) and PLA with graphene (GnP) in fused deposition modeling (FDM). Int. J. Plast. Technol. 2019, 23, 195-206. [CrossRef]

17. MacDonald, E.; Salas, R.; Espalin, D.; Perez, M.; Aguilera, E.; Muse, D.; Wicker, R.B. 3D Printing for the Rapid Prototyping of Structural Electronics. IEEE Access 2014, 2, 234-242. [CrossRef]

18. Bailey, C.; Stoyanov, S.; Tilford, T.; Tourloukis, G. 3D-Printing and Electronic Packaging. In Proceedings of the 2016 Pan Pacific Microelectronics Symposium, Pan Pacific 2016, Kohala Coast, HI, USA, 25-28 January 2016.

19. Aspar, G.; Goubault, B.; Lebaigue, O.; Souriau, J.C.; Simon, G.; di Cioccio, L.; Brechet, Y. 3D Printing as a New Packaging Approach for MEMS and Electronic Devices. In Proceedings of the Proceedings-Electronic Components and Technology Conference, Orlando, FL, USA, 30 May-2 June 2017; pp. 1071-1079.

20. Conrad, M.; de Doncker, R.W.; Schniedenharn, M.; Diatlov, A. Packaging for Power Semiconductors Based on the 3D Printing Technology Selective Laser Melting. In Proceedings of the 2014 16th European Conference on Power Electronics and Applications, EPE-ECCE Europe 2014, Lappeenranta, Finland, 26-28 August 2014.

21. Tack, P.; Victor, J.; Gemmel, P.; Annemans, L. 3D-Printing Techniques in a Medical Setting: A Systematic Literature Review. BioMedical Eng. Online 2016, 15, 1-21. [CrossRef]

22. Vidakis, N.; Petousis, M.; Velidakis, E.; Mountakis, N.; Tzounis, L.; Liebscher, M.; Grammatikos, S.A. Enhanced Mechanical, Thermal and Antimicrobial Properties of Additively Manufactured Polylactic Acid with Optimized Nano Silica Content. Nanomaterials 2021, 11, 1012. [CrossRef]

23. Vidakis, N.; Petousis, M.; Velidakis, E.; Liebscher, M.; Tzounis, L. Three-Dimensional Printed Antimicrobial Objects of Polylactic Acid (PLA)-Silver Nanoparticle Nanocomposite Filaments Produced by an In-Situ Reduction Reactive Melt Mixing Process. Biomimetics 2020, 5, 42. [CrossRef]

24. Sa, L.; Kaiwu, L.; Shenggui, C.; Junzhong, Y.; Yongguang, J.; Lin, W.; Li, R. 3D Printing Dental Composite Resins with Sustaining Antibacterial Ability. J. Mater. Sci. 2019, 54, 3309-3318. [CrossRef]

25. Vidakis, N.; Vairis, A.; Petousis, M.; Savvakis, K.; Kechagias, J. Fused deposition modelling parts tensile strength characterisation Acad. J. Manuf. Eng. 2016, 14, 87-94. 
26. Bhadeshia, H.K.D.H. Additive Manufacturing. Mater. Sci. Technol. 2016, 32, 615-616. [CrossRef]

27. Vidakis, N.; Petousis, M.; Velidakis, E.; Liebscher, M.; Mechtcherine, V.; Tzounis, L. On the strain rate sensitivity of fused filament fabrication (Fff) processed pla, abs, petg, pa6, and pp thermoplastic polymers. Polymers 2020, 12, 2924. [CrossRef] [PubMed]

28. Gebler, M.; Schoot Uiterkamp, A.J.M.; Visser, C. A Global Sustainability Perspective on 3D Printing Technologies. Energy Policy 2014, 74, 158-167. [CrossRef]

29. Vidakis, N.; Petousis, M.; Velidakis, E.; Tzounis, L.; Mountakis, N.; Korlos, A.; Fischer-Griffiths, P.E.; Grammatikos, S. On the Mechanical Response of Silicon Dioxide Nanofiller Concentration on Fused Filament Fabrication 3d Printed Isotactic Polypropylene Nanocomposites. Polymers 2021, 13, 2029. [CrossRef]

30. Fernandes, J.; Deus, A.M.; Reis, L.; Vaz, M.F.; Leite, M. Study of the Influence of 3D Printing Parameters on the Mechanical Properties of PLA. Proc. Int. Conf. Prog. Addit. Manuf. 2018, 2018, 547-552. [CrossRef]

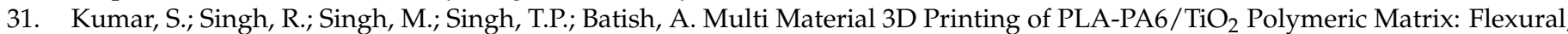
Wear and Morphological Properties. J. Thermoplast. Compos. Mater. 2020, 0892705720953193. [CrossRef]

32. Vidakis, N.; Petousis, M.; Vairis, A.; Savvakis, K.; Maniadi, A. A parametric determination of bending and Charpy's impact strength of ABS and ABS-plus fused deposition modeling specimens. Prog. Addit. Manuf. 2019, 4, 323-330. [CrossRef]

33. Dong, J.; Mei, C.; Han, J.; Lee, S.; Wu, Q. 3D Printed Poly(Lactic Acid) Composites with Grafted Cellulose Nanofibers: Effect of Nanofiber and Post-Fabrication Annealing Treatment on Composite Flexural Properties. Addit. Manuf. 2019, 28, 621-628. [CrossRef]

34. Savvakis, K.; Petousis, M.; Vairis, A.; Vidakis, N.; Bikmeyev, A. Imece2014-37553 Deposition Modeling Parts. ASME 2014 Int. Mech. Eng. Congr. Expo. 2014, 14, V014T11A022.

35. Vidakis, N.; Petousis, M.; Tzounis, L.; Velidakis, E.; Mountakis, N.; Grammatikos, S.A. Polyamide 12/Multiwalled Carbon Nanotube and Carbon Black Nanocomposites Manufactured by 3D Printing Fused Filament Fabrication: A Comparison of the Electrical, Thermoelectric, and Mechanical Properties. C 2021, 7, 38. [CrossRef]

36. Espera, A.H.; Valino, A.D.; Palaganas, J.O.; Souza, L.; Chen, Q.; Advincula, R.C. 3D Printing of a Robust Polyamide-12-Carbon Black Composite via Selective Laser Sintering: Thermal and Electrical Conductivity. Macromol. Mater. Eng. 2019, $304,1800718$. [CrossRef]

37. Rahim, T.N.A.T.; Abdullah, A.M.; Akil, H.M.; Mohamad, D.; Rajion, Z.A. The Improvement of Mechanical and Thermal Properties of Polyamide 12 3D Printed Parts by Fused Deposition Modelling. Express Polym. Lett. 2017, 11, 963-982. [CrossRef]

38. Lupone, F.; Padovano, E.; Casamento, F.; Badini, C. Process Phenomena and Material Properties in Selective Laser Sintering of Polymers: A Review. Materials 2022, 15, 183. [CrossRef]

39. Goodridge, R.D.; Tuck, C.J.; Hague, R.J.M. Laser sintering of polyamides and other polymers. Prog. Mater. Sci. 2012, 57, 229-267. [CrossRef]

40. Ma, X.L. Research on Application of SLA Technology in the 3D Printing Technology. Appl. Mech. Mater. 2013, 401-403, 938-941. [CrossRef]

41. Mubarak, S.; Dhamodharan, D.; B. Kale, M.; Divakaran, N.; Senthil, T.; Wu, L.; Wang, J. A Novel Approach to Enhance Mechanical and Thermal Properties of SLA 3D Printed Structure by Incorporation of Metal-Metal Oxide Nanoparticles. Nanomaterials 2020, 10, 217. [CrossRef] [PubMed]

42. Ambrosio, D.; Gabrion, X.; Malécot, P.; Amiot, F.; Thibaud, S. Influence of Manufacturing Parameters on the Mechanical Properties of Projection Stereolithography-Manufactured Specimens. Int. J. Adv. Manuf. Technol. 2020, 106, 265-277. [CrossRef]

43. Borrello, J.; Nasser, P.; Iatridis, J.C.; Costa, K.D. 3D Printing a Mechanically-Tunable Acrylate Resin on a Commercial DLP-SLA Printer. Addit. Manuf. 2018, 23, 374-380. [CrossRef]

44. Manapat, J.Z.; Chen, Q.; Ye, P.; Advincula, R.C. 3D Printing of Polymer Nanocomposites via Stereolithography. Macromol. Mater. Eng. 2017, 302, 1-13. [CrossRef]

45. Kleverlaan, C.J.; Feilzer, A.J. Polymerization Shrinkage and Contraction Stress of Dental Resin Composites. Dent. Mater. 2005, 21, 1150-1157. [CrossRef] [PubMed]

46. Weng, Z.; Zhou, Y.; Lin, W.; Senthil, T.; Wu, L. Structure-Property Relationship of Nano Enhanced Stereolithography Resin for Desktop SLA 3D Printer. Compos. Part A Appl. Sci. Manuf. 2016, 88, 234-242. [CrossRef]

47. Martínez-Pellitero, S.; Castro, M.A.; Fernández-Abia, A.I.; González, S.; Cuesta, E. Analysis of Influence Factors on Part Quality in Micro-SLA Technology. Procedia Manuf. 2017, 13, 856-863. [CrossRef]

48. Slapnik, J.; Pulko, I. Tailoring Properties of Photopolymers for Additive Manufacturing with Mixture Design. Prog. Addit. Manuf. 2021, 6, 83-91. [CrossRef]

49. Chun, D.M. The Role of Technology in SLA Research. Lang. Learn. Technol. 2016, 20, 98-115.

50. Advincula, R.C.; Dizon, J.R.C.; Chen, Q.; Niu, I.; Chung, J.; Kilpatrick, L.; Newman, R. Additive Manufacturing for COVID-19: Devices, Materials, Prospects, and Challenges. MRS Commun. 2020, 10, 413-427. [CrossRef]

51. Tarfaoui, M.; Nachtane, M.; Goda, I.; Qureshi, Y.; Benyahia, H. Additive Manufacturing in Fighting against Novel Coronavirus COVID-19. Int. J. Adv. Manuf. Technol. 2020, 110, 2913-2927. [CrossRef]

52. Tareq, M.S.; Rahman, T.; Hossain, M.; Dorrington, P. Additive Manufacturing and the COVID-19 Challenges: An in-Depth Study. J. Manuf. Syst. 2021, 60, 787-798. [CrossRef]

53. Patel, P.; Gohil, P. Role of Additive Manufacturing in Medical Application COVID-19 Scenario: India Case Study. J. Manuf. Syst. 2021, 60, 811-822. [CrossRef] 
54. Kunovjanek, M.; Wankmüller, C. An Analysis of the Global Additive Manufacturing Response to the COVID-19 Pandemic. J. Manuf. Technol. Manag. 2020, 32, 75-100. [CrossRef]

55. Larrañeta, E.; Dominguez-Robles, J.; Lamprou, D.A. Additive Manufacturing Can Assist in the Fight against COVID-19 and Other Pandemics and Impact on the Global Supply Chain. 3D Print. Addit. Manuf. 2020, 7, 100-103. [CrossRef]

56. Bishop, E.G.; Leigh, S.J. Using Large-Scale Additive Manufacturing (LSAM) as a Bridge Manufacturing Process in Response to Shortages in PPE during the COVID-19 Outbreak. Int. J. Bioprinting 2020, 6, 51-58. [CrossRef] [PubMed]

57. Son, K.; Lee, J.H.; Lee, K.B. Comparison of Intaglio Surface Trueness of Interim Dental Crowns Fabricated with Sla 3d Printing, Dlp 3d Printing, and Milling Technologies. Healthcare 2021, 9, 983. [CrossRef] [PubMed]

58. Meghana, S.; Kabra, P.; Chakraborty, S.; Padmavathy, N. Understanding the pathway of antibacterial activity of copper oxide nanoparticles. RSC Adv. 2015, 5, 12293-12299. [CrossRef]

59. Bezza, F.A.; Tichapondwa, S.M.; Chirwa, E.M.N. Fabrication of monodispersed copper oxide nanoparticles with potential application as antimicrobial agents. Sci. Rep. 2020, 10, 16680. [CrossRef]

60. Bouzakis, K.D.; Vidakis, N. Superficial plastic response determination of hard isotropic materials using ball indentations and a FEM optimization technique. Mater. Charact. 1999, 42, 1-12. [CrossRef]

61. Papi, M.; Palmieri, V.; Bugli, F.; De Spirito, M.; Sanguinetti, M.; Ciancico, C.; Braidotti, M.C.; Gentilini, S.; Angelani, L.; Conti, C. Biomimetic antimicrobial cloak by graphene-oxide agar hydrogel. Sci. Rep. 2016, 6, 1-7. [CrossRef] 